\title{
Hypertrophic olivary degeneration secondary to traumatic brain injury: a unique form of trans-synaptic degeneration
}

Raman Mehrzad, ${ }^{1}$ Michael G Ho ${ }^{2}$

${ }^{1}$ Department of Medicine, Steward Carney Hospital, Tufts University School of Medicine, Boston, Massachusetts, USA ${ }^{2}$ Department of Neurology, Steward Carney Hospital, Tufts University School of Medicine, Boston, Massachusetts, USA

\section{Correspondence to}

Dr Raman Mehrzad

raman_m1@hotmail.com

\section{Accepted 11 June 2015}

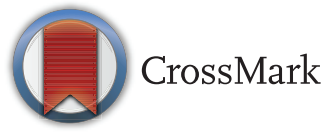

To cite: Mehrzad $\mathrm{R}$ Ho MG. BMJ Case Rep Published online: [please include Day Month Year] doi:10.1136/bcr-2015-

210334

\section{DESCRIPTION}

A 33-year-old man with a history of traumatic brain injury (TBI) from a few years prior, secondary to a high-speed motor vehicle accident, presented with worsening right-sided motor function. Brain MRI showed diffuse axonal injury, punctuate microbleedings, asymmetric Wallerian degeneration along the left corticospinal tract in the brainstem and

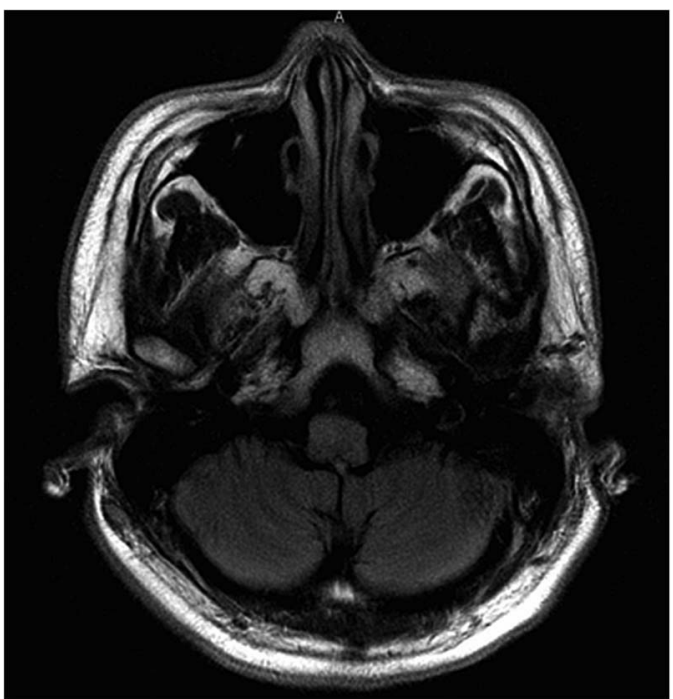

Figure 1 Brain axial fluid-attenuated inversion recovery MRI showing hypertrophy of the right inferior olivary nucleus.

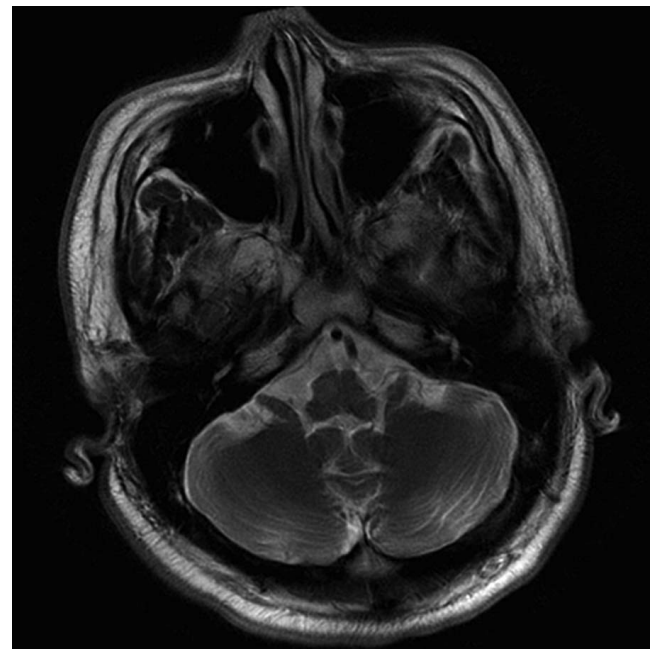

Figure 2 Brain axial T2 MRI showing increased T2 signal change and hypertrophy of the right inferior olivary nucleus. haemorrhagic left superior cerebellar peduncle, all consistent with his prior TBI. Moreover, the right inferior olivary nucleus was enlarged, which is exemplified in unilateral right hypertrophic olivary degeneration (HOD), likely secondary to the haemorrhagic lesion within the left superior cerebellar peduncle, causing secondary degeneration of the contralateral corticospinal tracts (figures 1-6).

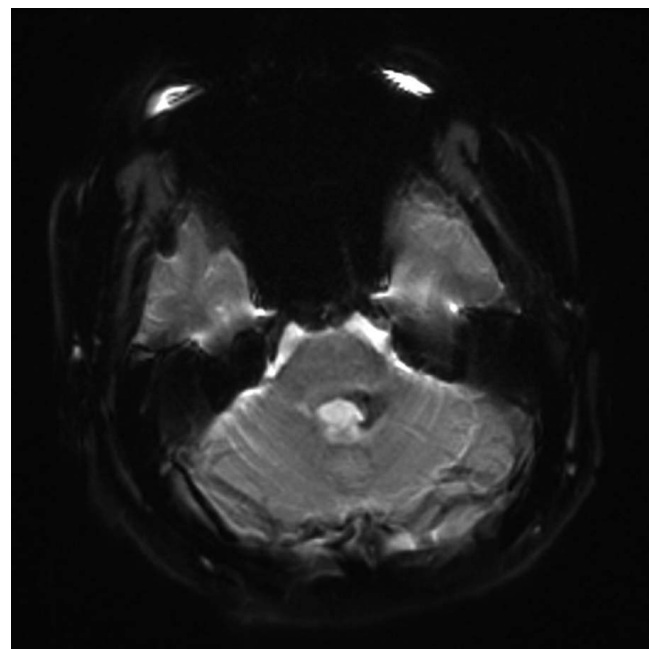

Figure 3 Brain axial gradient echo MRI showing haemosiderin products in the left superior cerebellar peduncle.

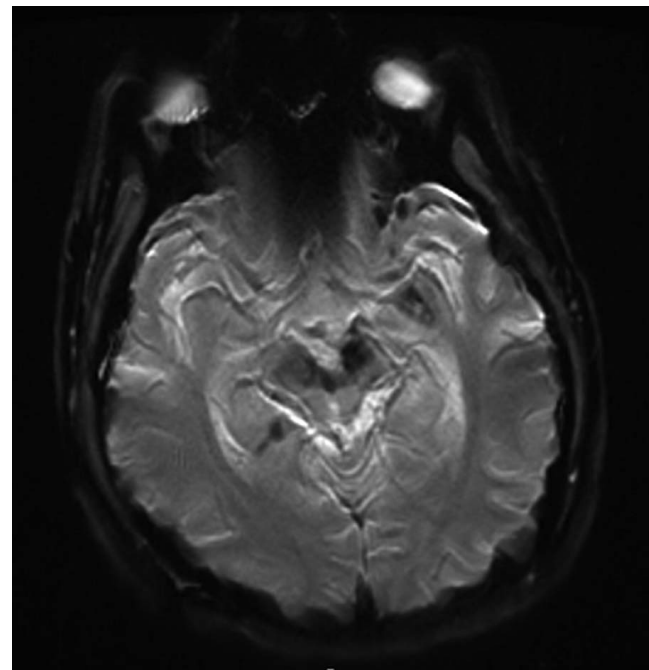

Figure 4 Brain axial gradient echo MRI showing evidence of haemosiderin products in the left $>$ right midbrain, cerebral peduncles and temporal lobes. 


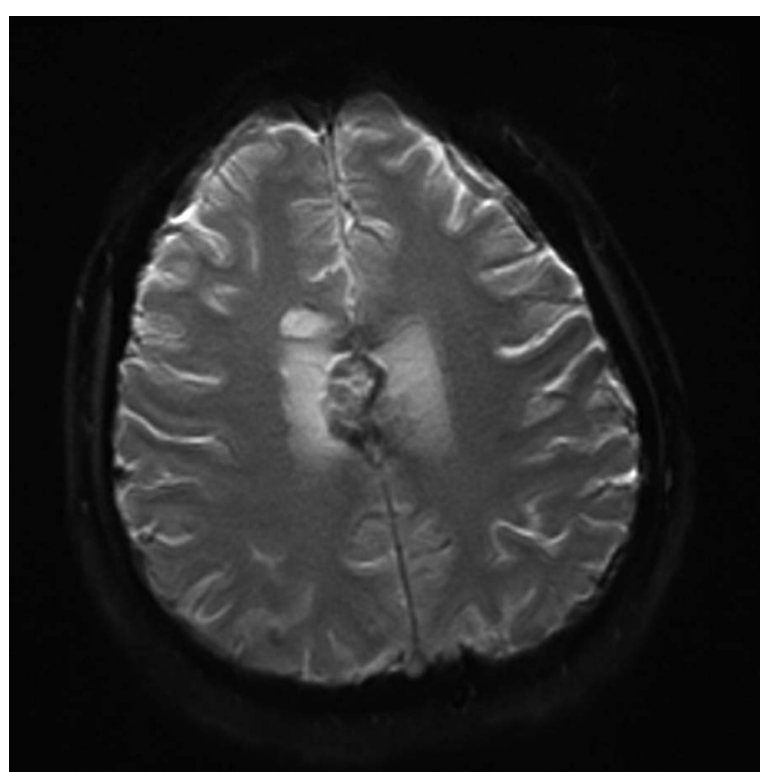

Figure 5 Brain axial gradient echo MRI sequence showing severe microhaemorrhages throughout the body of the corpus callosum.

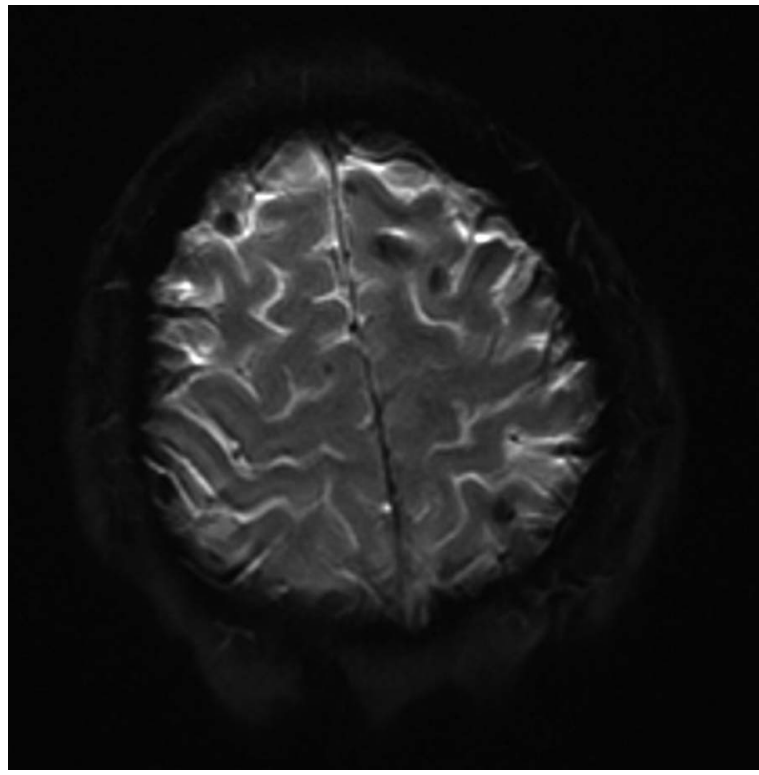

Figure 6 Brain axial gradient echo MRI showing haemosiderin products in the cortical/subcortical regions of bilateral frontal and parietal lobes.
HOD is a very rare form of trans-synaptic degeneration that occurs over a long period of time when a lesion interrupts the triangle of Guillain-Mollaret. ${ }^{1}$ Damage to either the anterior spinocerebellar tracts or cerebellar efferences, which mainly run from the dentate nucleus via the superior cerebellar peduncle to the red nucleus and thalamus (dentatorubral tract), may explain our patient's marked cerebellar syndrome. The dentatorubral tract constitutes one component of the triangle of Guillain-Mollaret, which is a functional neuronal network arranged in a feedback loop encompassing the cerebellum including the dentate nucleus, red nucleus and the inferior olivary nucleus. Fibres run from the dentate nucleus via the dentatorubral tract within the superior cerebellar peduncle to the contralateral red nucleus. Fibres from the red nucleus project to the inferior olive via the central tegmental tract, and from there, olivocerebellar fibres run via the inferior cerebellar peduncle to the contralateral cerebellar cortex, which projects to the dentate nucleus. $^{2}$

\section{Learning points}

Hypertrophic olivary degeneration is a very rare form of trans-synaptic degeneration that occurs over a long period of time when a lesion interrupts the triangle of Guillain-Mollaret.

- Haemorrhagic lesion within the left superior cerebellar peduncle causes secondary degeneration of the contralateral corticospinal tracts, which causes this unique finding.

Competing interests None declared.

Patient consent Obtained.

Provenance and peer review Not commissioned; externally peer reviewed.

\section{REFERENCES}

1 Guillain G, Mollaret P. Deux cas de myoclonies synchrones et rhythmes velopharyngo-laryngooculo- diaphragmatiques. Rev Neurol 1931;2: 545-66.

2 Goto N, Kaneko M. Olivary enlargement: chronological and morphometric analyses. Acta Neuropathol 1981:54:275-82.

Copyright 2015 BMJ Publishing Group. All rights reserved. For permission to reuse any of this content visit http://group.bmj.com/group/rights-licensing/permissions.

BMJ Case Report Fellows may re-use this article for personal use and teaching without any further permission.

Become a Fellow of BMJ Case Reports today and you can:

- Submit as many cases as you like

- Enjoy fast sympathetic peer review and rapid publication of accepted articles

- Access all the published articles

- Re-use any of the published material for personal use and teaching without further permission

For information on Institutional Fellowships contact consortiasales@bmjgroup.com

Visit casereports.bmj.com for more articles like this and to become a Fellow 